\title{
Hepcidin deficiency undermines bone load-bearing capacity through inducing iron overload
}

\author{
Li Sun $^{\mathrm{a}, \mathrm{b}, 1}$, Wenli Guo b,1 ${ }^{\text {, Chunyang Yin }}{ }^{\mathrm{b}}$, Shuping Zhang ${ }^{\mathrm{b}}$, Guangbo Qu ${ }^{\mathrm{b}}$, Yanli Hou ${ }^{\mathrm{c}}$, Haiqin Rong ${ }^{\mathrm{c}}$, \\ Hong $\mathrm{Ji}^{\mathrm{c}, *}$, Sijin Liu ${ }^{\mathrm{b}, *}$ \\ a School of Medicine and Life Sciences, University of Jinan-Shandong Academy of Medical Sciences, Jinan 250062, China \\ b State Key Laboratory of Environmental Chemistry and Ecotoxicology, Research Center for Eco-Environmental Sciences, Chinese Academy of Sciences, Beijing 100085, China \\ c Shandong Institute of Endocrine and Metabolic Diseases, Shandong Academy of Medical Sciences, Jinan 250062, China
}

\section{A R T I C L E I N F O}

\section{Article history:}

Received 5 December 2013

Received in revised form 24 January 2014

Accepted 4 February 2014

Available online 19 February 2014

\section{Keywords:}

Hepcidin deficiency

Iron overload

Bone resorption

Bone strength

\begin{abstract}
A B S T R A C T
Osteoporosis is one of the leading disorders among aged people. Bone loss results from a number of physiological alterations, such as estrogen decline and aging. Meanwhile, iron overload has been recognized as a risk factor for bone loss. Systemic iron homeostasis is fundamentally governed by the hepcidin-ferroportin regulatory axis, where hepcidin is the key regulator. Hepcidin deficiency could induce a few disorders, of which iron overload is the most representative phenotype. However, there was little investigation of the effects of hepcidin deficiency on bone metabolism. To this end, hepcidin-deficient $\left(\right.$ Hamp $\left.^{-/-}\right)$mice were employed to address this issue. Our results revealed that significant iron overload was induced in Hamp $1^{-/}$mice. Importantly, significant decreases of maximal loading and maximal bending stress were found in Hamp $1^{-/}$mice relative to wildtype (WT) mice. Moreover, the levels of the C-telopeptide of type I collagen (CTX-1) increased in Hamp $1^{-1-}$ mice. Therefore, hepcidin deficiency resulted in a marked reduction of bone load-bearing capacity likely through enhancing bone resorption, suggesting a direct correlation between hepcidin deficiency and bone loss. Targeting hepcidin or the pathway it modulates may thus represent a therapeutic for osteopenia or osteoporosis.
\end{abstract}

(c) 2014 Elsevier B.V. All rights reserved.

\section{Introduction}

According to the data of the World Health Organization, osteoporosis has become a global issue and an increasing threat to human health (Alexandre, 1995). Osteoporosis is a common disease characterized by low bone mineral mass, associated with a high incidence of bone fractures (Cooper and Aihie, 1995; Guggenbuhl et al., 2005). Bone metabolism is maintained through a kinetic balance between formation and resorption. Bone formation is performed by osteoblasts, while bone resorption is carried out by osteoclasts (Fohr et al., 2003; Mizuno et al., 1998; Suda et al., 1996). Disruption of this balance is likely associated with bone loss (Suda et al., 1996). There are a number of factors that may account for osteopenia or osteoporosis, such as estrogen deficiency and abnormal calcium metabolism (Chevalley et al., 1994; Kanis, 1994). Additionally, Delbarre and his colleagues reported that osteoporosis is a complication of hereditary hemochromatosis $(\mathrm{HH})$ half a century ago (Delbarre, 1964). Since then, a number of clinical and experimental

Abbreviations: WT, wildtype; CTX-1, C-telopeptide of type I collagen; HH, hemochromatosis; HFE, hemochromatosis; BMP, bone morphogenetic protein; PBS, phosphatebuffered saline; OD, optical density; ROS, reactive oxygen species.

* Corresponding authors.

E-mail address: sjliu@rcees.ac.cn (S. Liu).

1 These authors equally contribute to this work. studies have documented that iron overload represents a risk factor responsible for bone loss, especially in patients suffering from $\mathrm{HH}$ (Guggenbuhl et al., 2011a), African hemosiderosis (Lorincz et al., 1974), thalassemia (Salama et al., 2006), sickle cell disease (AdamsGraves et al., 2013), and liver diseases (Diamond et al., 1990). A recent study described that $25 \%$ of $\mathrm{HH}$ patients were diagnosed with osteoporosis and $41 \%$ developed osteopenia (Valenti et al., 2009). HH is a genetic disorder, associated with iron overload in various organs (Fleming and Sly, 2002). In parallel to this finding, hemochromatosis (HFE)-deficient male mice, a mouse model of $\mathrm{HH}$, developed osteoporosis with low bone mass (Guggenbuhl et al., 2005, 2011b). Meanwhile, numerous clinical studies suggested that patients with osteoporosis accompanied iron accumulation in bone (Jian et al., 2009). Together, iron homeostasis is closely coupled to bone metabolism, and excessive iron accumulation is recognized as a risk factor for osteoporosis (Haidar et al., 2011; Kudo et al., 2008; Tsay et al., 2010; Valenti et al., 2009).

Iron homeostasis is fundamentally governed by the hepcidinferroportin regulatory axis (Park et al., 2001). Hepcidin, a 25 amino acid peptide, is the master hormone in modulating systemic iron homeostasis (Ganz, 2011). Its transcription is stimulated by iron, inflammatory cytokines and bone morphogenetic proteins (BMPs), and repressed by signaling from anemia and hypoxia (Ganz, 2011). Hepcidin inhibits iron egress out of cells through binding and inducing degradation of its receptor ferroportin. Ferroportin, the only known 
mammalian iron exporter is mainly expressed in epithelial cells in duodenum and macrophages (Jelic et al., 2013; Pinnix et al., 2010). Suppression of hepcidin expression or hepcidin deficiency would cause enhanced iron egress out of macrophages, leading to iron overload in various organs, associated with neoplasia, arthropathy and neurodegenerative diseases (Jelic et al., 2013; Pinnix et al., 2010).

However, there was still no investigation of the effects of hepcidin deficiency on bone metabolism. To this end, we used the hepcidindeficient (hepcidin knockout, Hamp $1^{-/-}$) mice to study bone metabolism under the setting of disordered iron homeostasis. We overall demonstrated that iron overload due to hepcidin deficiency greatly undermined bone strength and bone load-bearing capacity. Thus, targeting hepcidin or the signaling it mediates may represent a novel therapeutic for osteoporosis.

\section{Materials and methods}

\subsection{Animal experiment}

Hamp $1^{-/-}$mice were originally provided by Dr. Sophie Vaulont (Lesbordes-Brion et al., 2006) and currently with the C57BLK/6 background (Ramos et al., 2012). All mice were housed in the central animal facility of the Institute of Genetics and Developmental Biology, Chinese Academy of Sciences. Male Hamp $1^{-/-}$mice and wildtype (WT) mice with the same genetic background were sacrificed at 8 weeks, 18 weeks and 30 weeks. Sera and organ specimens were collected. Tibias were removed and packed in gauze soaked with phosphate-buffered saline (PBS), and stored at $-80^{\circ} \mathrm{C}$ for future analyses.

\subsection{Iron parameters}

Serum iron concentration was determined with a serum iron detection kit (Nanjing Jiancheng Bioengineering Institute, Nanjing, China). Hepatic iron content was assessed as previously described (Liu et al., $2007,2008)$. Briefly, the specimens of liver were digested by the acid solution for $72 \mathrm{~h}$ at $65{ }^{\circ} \mathrm{C}$. Thereafter, chromagen working solution was added. Finally, absorption at $535 \mathrm{~nm}$ was determined with a plate reader (Thermo).

\subsection{Assessments of bone metabolic markers}

Serum osteocalcin and C-telopeptide of type I collagen (CTX-1) were assayed by ELISA (Rapidbio; RapidBio, West Hills, CA, USA), according to the manufacturer's instructions. Briefly, the samples and standards were added into 96-well plates, and then incubated for $30 \mathrm{~min}$ at $37{ }^{\circ} \mathrm{C}$. After washing five times, HRP-conjugate reagent was added, followed by another round of incubation and washing. Optical density (OD) at $450 \mathrm{~nm}$ was measured after adding stop solution within 15 min. Finally, serum osteocalcin and CTX-1 concentrations were calculated according to the standard curves.

\subsection{Bone biomechanical analyses}

Biomechanical properties of tibias were determined by the threepoint bending test using a universal material test machine (AG-1S; Shimadzu Co., Kyoto, Japan) at room temperature, as described in previous studies (Mattila et al., 1999; Yamasaki and Hagiwara, 2009). The distance between the supporting rods had a fixed length (L) of $12 \mathrm{~mm}$. Load was applied at a constant deformation rate of $2 \mathrm{~mm} / \mathrm{min}$. The diaphysis of the tibia was loaded until fracture occurred, which provided measurement of yield and fracture parameters. Yield represents the point at which the bone ceases to behave elastically. Data were automatically recorded in a computer interfaced to the testing machine, and a typical load-deformation curve was created. The material properties of bone including the maximal loading and maximal bending stress were calculated according to the established formulas (Mattila et al., 1999; Yamasaki and Hagiwara, 2009). PBS was used to keep specimens moist during testing.

\subsection{Statistical analysis}

The SPSS Statistics 17.0 package was utilized to analyze the date. One-way analysis of variance (ANOVA) was applied to determine the mean differences among groups compared to the control. The difference between two groups was determined using the independent $t$-test. Data were shown in mean \pm SD. $\mathrm{P}<0.05$ was considered statistically significant.

\section{Results}

\subsection{Systemic iron overload in hepcidin-deficient mice}

To look into iron concentrations of Hamp $1^{-/-}$mice, we compared serum and tissue iron concentrations between hepcidin-deficient mice and WT mice of different ages. As shown in Fig. 1a, serum iron level was increased by approximately $25 \%$ in Hamp $1^{-1-}$ mice relative to WT mice at 8 weeks $(\mathrm{p}<0.05)$. This difference became even greater when mice got older, as evidenced by over $40 \%$ and $50 \%$ increase of serum iron in Hamp $1^{-1-}$ mice compared to WT mice at 18 weeks and 30 weeks, respectively (Fig. $1 \mathrm{a}, \mathrm{p}<0.05$ ). Moreover, there was a clear time-dependent increase of serum iron for Hamp $1^{-1-}$ mice from 8 weeks to 30 weeks (Fig. 1a, p < 0.05). However, the serum iron level remained consistent in WT mice over the time course from 8 weeks to 30 weeks (Fig. 1a, P > 0.05). Similarly, liver iron content was greatly increased in Hamp $1^{-1-}$ mice compared to WT mice for all ages tested (Fig. 1b, p < 0.05). There was an increase of liver iron concentrations in a time-dependent manner (Fig. $1 \mathrm{~b}, \mathrm{p}<0.05$ ), and hepatic iron concentrations were similar at different ages (Fig. 1b). Consistent with previous findings (Masaratana et al., 2011), our date revealed that hepcidin deficiency led to remarkable systemic iron overload, as reflected by increased serum iron and hepatic iron.
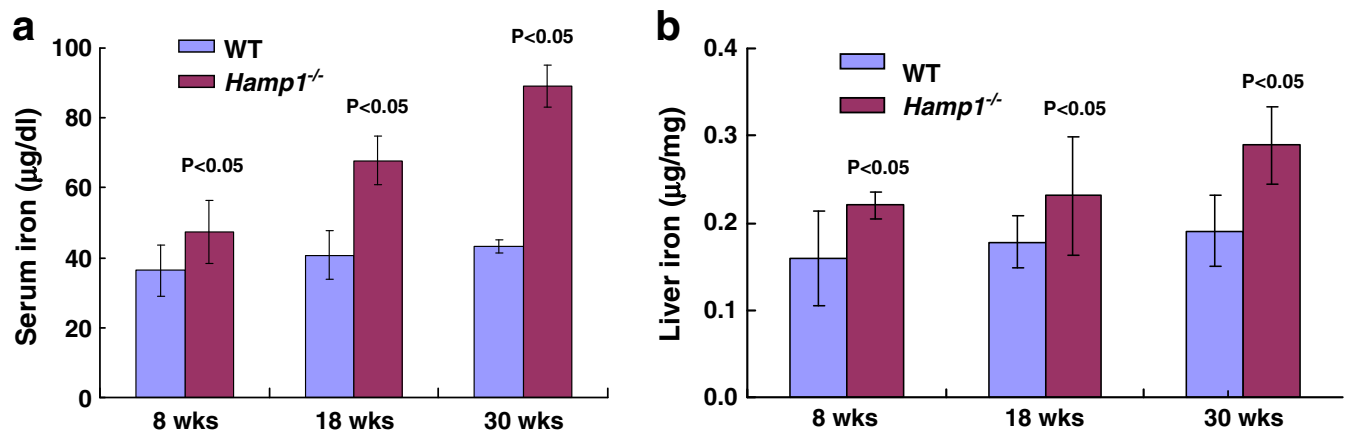

Fig. 1. Iron content in WT mice and Hamp1 $1^{-1-}$ mice at different ages. Serum iron (a) and hepatic iron (b) were shown ( $\left.\mathrm{n}=4-5\right)$. 

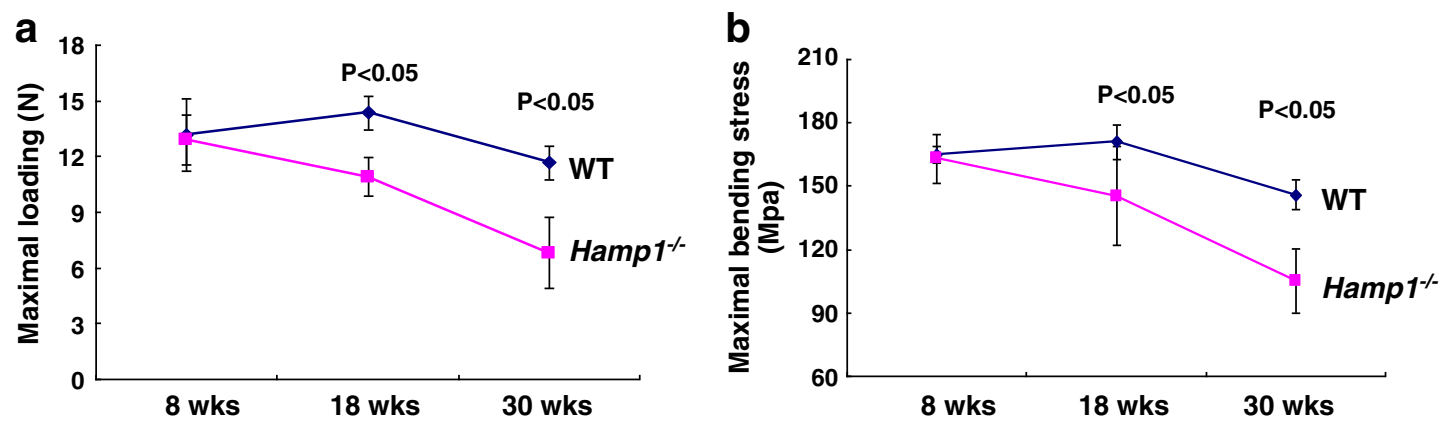

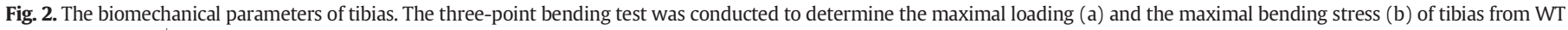
mice and Hamp $1^{-1-}$ mice at 8 weeks, 18 weeks and 30 weeks $(n=4-5)$.

\subsection{Hepcidin deficiency undermined bone load-bearing capacity}

To investigate the alterations of bone strength devoid of hepcidin, the biomechanical parameters of bone were examined. As shown in Fig. 2a, the maximal loading of tibias was similar between WT mice and Hamp $1^{-1-}$ mice at the age of 8 weeks. The maximal loading was significantly reduced by $20 \%$ in $H a m p 1^{-1-}$ mice at the age of 18 weeks ( $p<0.05)$; however, it kept consistent for an 18 week old WT mice ( $p>0.05)$. More strikingly, the maximal loading was further reduced approximately by $50 \%$ when mice reached 30 week old for Hamp $1^{-1-}$ mice compared to that for mice of 8 week old (Fig. 2a, p $<0.05$ ). Meanwhile, the maximal loading was reduced by $12 \%$ only in WT mice when they were 30 week old, and it was still much greater (over 42\%) than that for hepcidin-deficient mice (Fig. 2a, p < 0.05). Similar to the changes of the maximal loading, the maximal bending was also declined in Hamp $1^{-/-}$mice compared to WT mice at the ages of 18 weeks and 30 weeks, especially at 30 weeks (Fig. 2 b, p < 0.05). In other words, the maximal bending stress declined more rapidly in hepcidin deficient mice compared to WT mice from 8 weeks to 30 weeks (Fig. $2 \mathrm{~b}, \mathrm{p}<0.05$ ). These results together demonstrated that hepcidin deficiency significantly impaired mechanical properties, especially for aged mice.

\subsection{Hepcidin deficiency enhanced bone resorption}

To elucidate the mechanism underlying impaired bone strength under hepcidin deficiency, we looked into possible alterations to the delicate balance between bone formation and bone resorption. Osteocalcin is secreted by osteoblasts in their maturation stage in order to sustain mineralization, and, thus, osteocalcin is widely used as a marker to recognize the activity of bone formation (Christenson et al., 2012; Fiore et al., 1984). CTX-1 is a degraded product of type I collagen, and it reflects the activity of osteoclast-conducted bone resorption (Lian et al., 1982). CTX-1 is thus used as a marker indicating osteoclastic activity and bone resorption (Reginster et al., 2001). Regarding serum osteocalcin concentration, it was similar at 8 weeks and 18 weeks for both WT and Hamp $1^{-/-}$mice, and no significant difference was found between WT and Hamp $1^{-1-}$ mice (Fig. 3a). Serum osteocalcin level was reduced by approximately $39 \%$ in both WT and Hamp $1^{-1-}$ mice at 30 weeks compared to that at 8 weeks or 18 weeks (Fig. 3a, p < 0.05). Consistent with previous studies, this finding suggested attenuation of bone formation activity in aged mice. There was only a slight decrease of serum osteocalcin in Hamp $1^{-1-}$ mice compared to that in WT mice at 30 weeks with no significant difference (Fig, 3a, p > 0.05), implying bone formation was not significantly undermined due to hepcidin deficiency. However, we observed a distinct pattern for the CTX-1 concentration changes between WT mice and Hamp $1^{-/-}$mice during aging. As shown in Fig. 3c, the CTX-1 level was consistent for WT mice at different ages of 8 weeks, 18 weeks and 30 weeks, indicating the activity of bone resorption was not significantly altered during aging. These results were similar to the previous observations that the osteoclastic capability in bone resorption retained at a similar level for aged mice relative to young mice (Hauschka and Carr, 1982; Lian and Gundberg, 1988). Importantly, we found that the CTX-1 concentration was increased by approximately $25 \%$ in Hamp $1^{-/-}$mice compared to WT mice at 8 weeks and 18 weeks (Fig. 3c, p < 0.05). And the CTX-1 concentration was further increased (by $32 \%$ ) in Hamp $1^{-1-}$ mice in comparison to WT mice at 30 weeks (Fig. 3c, p < 0.05). Moreover, there was a clear time-dependent increased of CTX-1 level in Hamp $1^{-1-}$ mice from 8 weeks to 30 weeks (Fig. 3c, p < 0.05), revealing hepcidin deficiency further instigated bone resorption over the time course. These date together demonstrated that hepcidin deficiency greatly promoted osteoclast-induced bone resorption, especially in old mice, without significantly affecting bone formation.
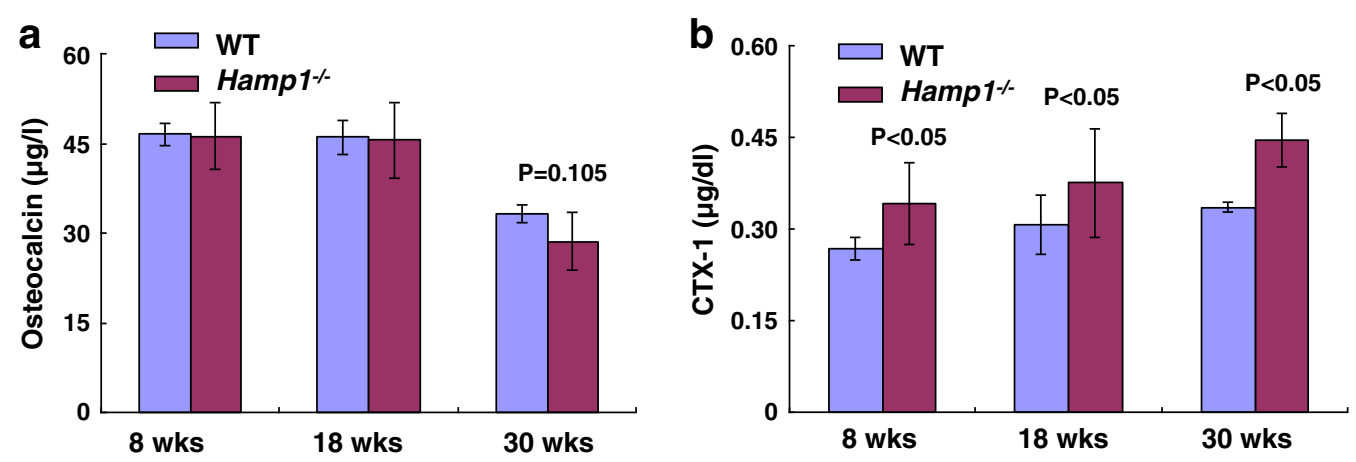

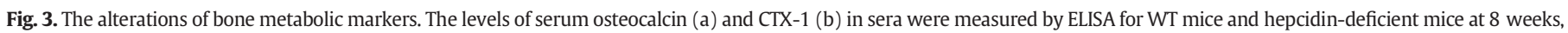
18 weeks and 30 weeks $(n=4-5)$. 


\section{Discussion}

Hepcidin plays a central role in maintaining iron homeostasis by suppressing iron absorption from duodenum and iron egress from cells (mainly macrophages and hepatocytes) by inducing degradation of iron exporter ferroportin (Nemeth and Ganz, 2009). Thus, the hepcidinferroportin regulatory axis fundamentally governs systematic iron homeostasis, through determining iron uptake, egress and localization (Andrews, 2008; Ganz, 2011; Knutson, 2010). Deregulated hepcidinferroportin axis is implicated in a wide spectrum of diseases, including iron diseases (Nemeth and Ganz, 2009), such as HH and anemia of inflammation, and various chronic diseases (e.g. cancers) (Brissot et al., 2011; Ganz et al., 2008; Kamai et al., 2009; Maes et al., 2010; Tanno et al., 2011). Hepcidin deficiency would lead to enforced iron absorption from duodenum and iron export from macrophages, leading to increased iron retention and even iron overload in various organs (Brissot et al., 2011; Ganz et al., 2008; Kamai et al., 2009; Maes et al., 2010; Tanno et al., 2011). In fact, hepcidin-null mice developed severe iron overload soon after weaning, similar to the phenotypes in $\mathrm{HH}$ patients with hepcidin mutations and $\beta$-thalassemia patients (Guggenbuhl et al., 2011a; Salama et al., 2006). As an essential element, iron is necessary for cell growth involving DNA synthesis, oxygen transport, energy metabolism and other cellular processes (Hentze et al., 2004). However, deregulated iron homeostasis contributes to the development of a variety of disorders (Cross et al., 2011; Hentze et al., 2004; Stevens et al., 1988; Wu et al., 2004). On one hand, iron deficit would lead to anemias (Jin et al., 2013); on the other hand, excess iron likely causes hepatic cirrhosis, hypopituitarism, cardiomyopathy, diabetes, arthritis, hyperpigmentation and neurodegeneration (Di Marco et al., 2008; Gama et al., 1995; JuanolaFalgarona et al., 2013; Lin et al., 2013; Song et al., 2013; Zhang et al., 2013). Moreover, accumulating data suggest that excess iron is associated with bone loss, as osteoporosis often accompanies iron overload in patients with $\mathrm{HH}$ and $\beta$-thalassemia (Kowdley, 2004; Lopez-Escribano et al., 2012; Schmidt et al., 2013; Szalay, 2013). Excess iron is likely a risk factor for osteoporosis; however, the mechanisms responsible for iron-mediated impairments to bone have not been recognized thus far.

In the current study, we found that hepcidin deficiency led to remarkable iron overload in Hamp $1^{-1-}$ mice, consistent with previous studies (Masaratana et al., 2011; Steinbicker et al., 2011). Hepcidindeficient mice revealed significant impairment of bone mechanical properties, as the maximal loading and the maximal bending stress were greatly diminished in Hamp $1^{-1-}$ mice. These results demonstrated a correlation between iron overload and bone fragility, and signified the contribution of excess iron to the development of osteoporosis ( $\mathrm{Li}$ et al., 2012; Yamasaki and Hagiwara, 2009). Further investigations indicated that bone formation process was not affected in hepcidin-null mice, as evidenced by a similar concentration between Hamp $1^{-/-}$ mice and WT mice at various ages. However, the process of bone resorption was significantly enforced by iron overload, as reflected by increased CTX-1 concentrations in hepcidin-null mice relative to WT mice for both young mice and aged mice. Therefore, our findings suggested that excess iron disrupted the elaborate balance between bone formation and bone resorption, and iron retention enhanced osteoclast-mediated bone resorption without affecting bone formation. In other words, excess iron promoted the activity of osteoclasts, and then elevated bone resorption process, with resultant loss of bone strength. In terms of the molecular mechanisms, previous studies have demonstrated that intracellular iron retention would cause massive production of reactive oxygen species (ROS) through Fenton reaction (Fridovich, 1978; Galaris and Pantopoulos, 2008; Halliwell and Gutteridge, 1990), and ROS is postulated to be an instigator of bone resorption (Jia et al., 2012). Jia and colleagues demonstrated that iron overload could promote osteoclast differentiation and bone resorption through stimulation of ROS (Ishii et al., 2009; Yamasaki and Hagiwara, 2009). A recent study also indicated that oxidative stress accounted for bone loss of iron overload mice (Tsay et al., 2010). Our own recent

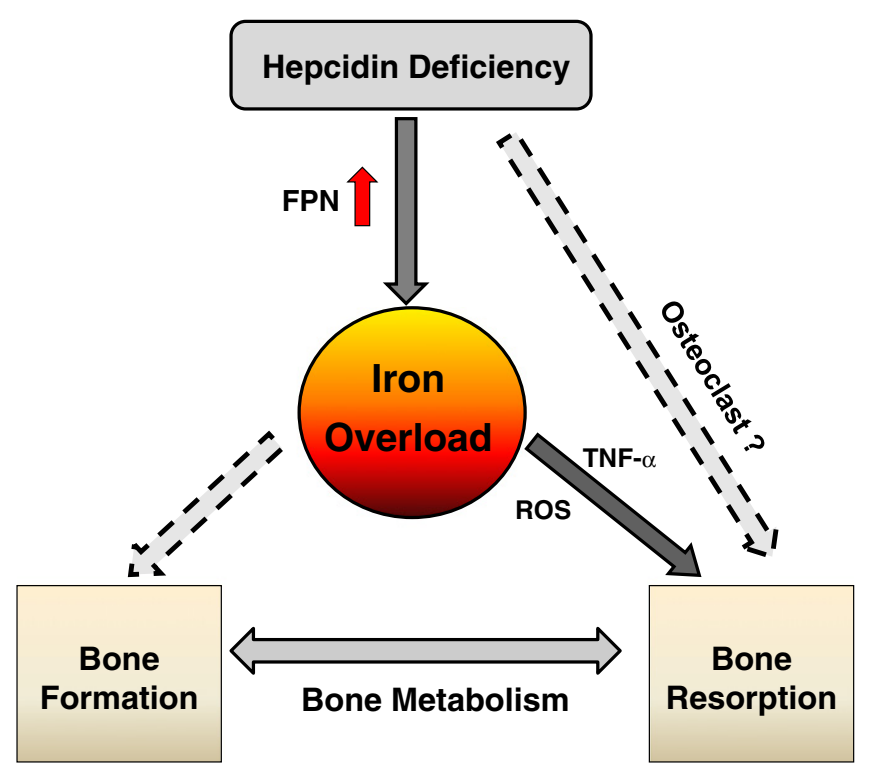

Fig. 4. A schematic delineating the mechanisms responsible for bone loss in absence of hepcidin.

study supported this statement that excess iron could stimulate bone resorption through TNF- $\alpha$-dependent osteoclastic activity in iron overload mice (Rong, 2012). In addition to hepatocytes, macrophages were also verified to express hepcidin, and macrophage hepcidin might play an important role in modulating inflammatory responses (Wu et al., 2012). Osteoclasts are a class of specialized macrophages in bone. However, whether hepcidin is also expressed in osteoclasts keeps unknown. Meanwhile, whether the absence of hepcidin activates osteoclasts and then stimulates bone resorptive activity warrants detailed investigation.

To summarize, our results highlighted a crucial role of hepcidin in maintaining bone metabolism. Hepcidin deficiency resulted in enhanced bone resorption and consequential bone loss, associated with impaired bone biomechanical properties, such as a large reduction of the maximal loading and the maximal bending stress. The loss of bone strength in the absence of hepcidin should result, at least mostly, from iron overload for hepcidin-null mice. A proposed schematic depicting the mechanisms underlying hepcidin deficiency-induced bone loss is illustrated in Fig. 4. The detailed molecular mechanisms certainly need further studies.

\section{Conflict of interest}

No potential conflicts of interest were disclosed from the authors. There are no non-financial competing interests to declare in relation to this manuscript.

\section{Acknowledgments}

This work was supported by a grant under the national "973" program (grant number: 2014CB932000) and the National Natural Science Foundation of China (grant number: 21377159). We thank Dr. Sophie Vaulont and Dr. Tomas Ganz for providing us hepcidin-null mice. We thank the laboratory members for their great assistance with the experiments and reagents.

\section{References}

Adams-Graves, P., Daniels, A.B., Womack, C.R., Freire, A.X., 2013. Bone mineral density patterns in vitamin D deficient African American men with sickle cell disease. Am. J. Med. Sci. http://dx.doi.org/10.1097/MAJ.0b013e3182893377.

Alexandre, C., 1995. Diagnosis and treatment of osteoporosis. Curr. Opin. Rheumatol. 7, 240-242. 
Andrews, N.C., 2008. Forging a field: the golden age of iron biology. Blood 112, 219-230.

Brissot, P., Bardou-Jacquet, E., Jouanolle, A.M., Loreal, O., 2011. Iron disorders of genetic origin: a changing world. Trends Mol. Med. 17, 707-713.

Chevalley, T., et al., 1994. Effects of calcium supplements on femoral bone mineral density and vertebral fracture rate in vitamin-D-replete elderly patients. Osteoporos. Int. 4 245-252.

Christenson, E.S., Jiang, X., Kagan, R., Schnatz, P., 2012. Osteoporosis management in postmenopausal women. Minerva Ginecol. 64, 181-194.

Cooper, C., Aihie, A., 1995. Osteoporosis. Baillieres Clin. Rheumatol. 9, 555-564.

Cross, A.J., et al., 2011. Iron homeostasis and distal colorectal adenoma risk in the prostate lung, colorectal, and ovarian cancer screening trial. Cancer Prev. Res. (Phila.) 4 $1465-1475$.

Delbarre, F., 1964. Osteoarticular manifestations of hemochromatosis. Presse Med. 72 2973-2978.

Di Marco, V., et al., 2008. Liver disease in chelated transfusion-dependent thalassemics: the role of iron overload and chronic hepatitis C. Haematologica 93, 1243-1246.

Diamond, T., Stiel, D., Lunzer, M., Wilkinson, M., Roche, J., Posen, S., 1990. Osteoporosis and skeletal fractures in chronic liver disease. Gut 31, 82-87.

Fiore, C.E., Malatino, L.S., Tamburino, G., 1984. Bone Gla-protein (osteocalcin): a new metabolic marker of calcified tissues. Recenti Prog. Med. 75, 361-381.

Fleming, R.E., Sly, W.S., 2002. Mechanisms of iron accumulation in hereditary hemochromatosis. Annu. Rev. Physiol. 64, 663-680.

Fohr, B., Dunstan, C.R., Seibel, M.J., 2003. Clinical review 165: markers of bone remodeling in metastatic bone disease. J. Clin. Endocrinol. Metab. 88, 5059-5075.

Fridovich, I., 1978. The biology of oxygen radicals. Science 201, 875-880.

Galaris, D., Pantopoulos, K., 2008. Oxidative stress and iron homeostasis: mechanistic and health aspects. Crit. Rev. Clin. Lab. Sci. 45, 1-23.

Gama, R., Smith, M.J., Wright, J., Marks, V., 1995. Hypopituitarism in primary haemochromatosis; recovery after iron depletion. Postgrad. Med. J. 71, 297-298.

Ganz, T., 2011. Hepcidin and iron regulation, 10 years later. Blood 117, 4425-4433.

Ganz, T., Olbina, G., Girelli, D., Nemeth, E., Westerman, M., 2008. Immunoassay for human serum hepcidin. Blood 112, 4292-4297.

Guggenbuhl, P., et al., 2005. Bone mineral density in men with genetic hemochromatosis and HFE gene mutation. Osteoporos. Int. 16, 1809-1814.

Guggenbuhl, P., Brissot, P., Loreal, O., 2011a. Miscellaneous non-inflammatory musculoskeletal conditions. Haemochromatosis: the bone and the joint. Best Pract. Res. Clin. Rheumatol. 25, 649-664.

Guggenbuhl, P., et al., 2011b. Bone status in a mouse model of genetic hemochromatosis Osteoporos. Int. 22, 2313-2319.

Haidar, R., Musallam, K.M., Taher, A.T., 2011. Bone disease and skeletal complications in patients with beta thalassemia major. Bone 48, 425-432.

Halliwell, B., Gutteridge, J.M., 1990. Role of free radicals and catalytic metal ions in human disease: an overview. Methods Enzymol. 186, 1-85.

Hauschka, P.V., Carr, S.A., 1982. Calcium-dependent alpha-helical structure in osteocalcin. Biochemistry 21, 2538-2547.

Hentze, M.W., Muckenthaler, M.U., Andrews, N.C., 2004. Balancing acts: molecular control of mammalian iron metabolism. Cell 117, 285-297.

Ishii, K.A., et al., 2009. Coordination of PGC-1beta and iron uptake in mitochondrial biogenesis and osteoclast activation. Nat. Med. 15, 259-266.

Jelic, M., et al., 2013. Hepcidin and iron metabolism disorders in patients with chronic kidney disease. Vojnosanit. Pregl. 70, 368-373.

Jia, P., et al., 2012. Ferric ion could facilitate osteoclast differentiation and bone resorption through the production of reactive oxygen species. J. Orthop. Res. 30 1843-1852.

Jian, J., Pelle, E., Huang, X., 2009. Iron and menopause: does increased iron affect the health of postmenopausal women? Antioxid. Redox Signal. 11, 2939-2943.

Jin, P., et al., 2013. Study on abnormal iron metabolism and iron overload in patients with aplastic anemia. Zhonghua Xue Ye Xue Za Zhi 34, 877-882.

Juanola-Falgarona, M., et al., 2013. Association between serum ferritin and osteocalcin as a potential mechanism explaining the iron-induced insulin resistance. PLoS One 8 , e76433.

Kamai, T., Tomosugi, N., Abe, H., Arai, K., Yoshida, K.-I., 2009. Increased serum hepcidin-25 level and increased tumor expression of hepcidin mRNA are associated with metastasis of renal cell carcinoma. BMC Cancer 9, 270.

Kanis, J.A., 1994. Assessment of fracture risk and its application to screening for postmenopausal osteoporosis: synopsis of a WHO report. WHO Study Group. Osteoporos. Int 4, 368-381.

Knutson, M.D., 2010. Iron-Sensing proteins that regulate hepcidin and enteric iron absorption. Annu. Rev. Nutr. 30, 149-171.

Kowdley, K.V., 2004. Iron, hemochromatosis, and hepatocellular carcinoma. Gastroenterology 127, S79-S86.

Kudo, H., Suzuki, S., Watanabe, A., Kikuchi, H., Sassa, S., Sakamoto, S., 2008. Effects of colloidal iron overload on renal and hepatic siderosis and the femur in male rats. Toxicology 246, 143-147.
Lesbordes-Brion, J.C., et al., 2006. Targeted disruption of the hepcidin 1 gene results in severe hemochromatosis. Blood 108, 1402-1405.

Li, G.F., Pan, Y.Z., Sirois, P., Li, K., Xu, Y.J., 2012. Iron homeostasis in osteoporosis and its clinical implications. Osteoporos. Int. 23, 2403-2408.

Lian, J.B., Gundberg, C.M., 1988. Osteocalcin. Biochemical considerations and clinical applications. Clin. Orthop. Relat. Res. 267-91.

Lian, J.B., Roufosse, A.H., Reit, B., Glimcher, M.J., 1982. Concentrations of osteocalcin and phosphoprotein as a function of mineral content and age in cortical bone. Calcif. Tissue Int. 34 (Suppl. 2), S82-S87.

Lin, H., Lian, W.S., Chen, H.H., Lai, P.F., Cheng, C.F., 2013. Adiponectin ameliorates ironoverload cardiomyopathy through the PPARalpha-PGC-1-dependent signaling pathway. Mol. Pharmacol. 84, 275-285.

Liu, S., et al., 2007. The function of heme-regulated eIF2alpha kinase in murine iron homeostasis and macrophage maturation. J. Clin. Invest. 117, 3296-3305.

Liu, S., Suragani, R.N., Han, A., Zhao, W., Andrews, N.C., Chen, J.J., 2008. Deficiency of hemeregulated eIF2alpha kinase decreases hepcidin expression and splenic iron in $\mathrm{HFE}^{-}$/ $^{-}$ mice. Haematologica 93, 753-756.

Lopez-Escribano, H., et al., 2012. Effect of co-inheritance of beta-thalassemia and hemochromatosis mutations on iron overload. Hemoglobin 36, 85-92.

Lorincz, G., Traub, N.E., Chuke, P.O., Hussain, S.F., 1974. African haemosiderosis associated with osteoporosis and vertebral collapse. East Afr. Med. J. 51, 488-495.

Maes, K., et al., 2010. In anemia of multiple myeloma, hepcidin is induced by increased bone morphogenetic protein 2. Blood 116, 3635-3644.

Masaratana, P., Laftah, A.H., Latunde-Dada, G.O., Vaulont, S., Simpson, R.J., McKie, A.T., 2011. Iron absorption in hepcidin1 knockout mice. Br. J. Nutr. 105, 1583-1591.

Mattila, P., Knuuttila, M., Kovanen, V., Svanberg, M., 1999. Improved bone biomechanical properties in rats after oral xylitol administration. Calcif. Tissue Int. 64, 340-344.

Mizuno, A., et al., 1998. Severe osteoporosis in mice lacking osteoclastogenesis inhibitory factor/osteoprotegerin. Biochem. Biophys. Res. Commun. 247, 610-615.

Nemeth, E., Ganz, T., 2009. The role of hepcidin in iron metabolism. Acta Haematol. 122, $78-86$

Park, C.H., Valore, E.V., Waring, A.J., Ganz, T., 2001. Hepcidin, a urinary antimicrobial peptide synthesized in the liver. J. Biol. Chem. 276, 7806-7810.

Pinnix, Z.K., et al., 2010. Ferroportin and iron regulation in breast cancer progression and prognosis. Sci. Transl. Med. 2, 43ra56.

Ramos, E., et al., 2012. Minihepcidins prevent iron overload in a hepcidin-deficient mouse model of severe hemochromatosis. Blood 120, 3829-3836.

Reginster, J.Y., et al., 2001. Bone resorption in post-menopausal women with normal and low BMD assessed with biochemical markers specific for telopeptide derived degradation products of collagen type I. Calcif. Tissue Int. 69, 130-137.

Rong, H., 2012. Excess iron undermined bone load-bearing capacity through tumor necrosis factor- $\alpha$-dependent osteoclastic activation in mice. Biomed. Rep. 1, 85-88.

Salama, O.S., Al-Tonbary, Y.A., Shahin, R.A., Eldeen, O.A., 2006. Unbalanced bone turnover in children with beta-thalassemia. Hematology 11, 197-202.

Schmidt, P.J., et al., 2013. An RNAi therapeutic targeting Tmprss6 decreases iron overload in $\operatorname{HFE}\left({ }^{-} /{ }^{-}\right)$mice and ameliorates anemia and iron overload in murine betathalassemia intermedia. Blood 121, 1200-1208.

Song, S.N., et al., 2013. Comparative evaluation of the effects of treatment with tocilizumab and TNF-alpha inhibitors on serum hepcidin, anemia response and disease activity in rheumatoid arthritis patients. Arthritis Res. Ther. 15, R141.

Steinbicker, A.U., et al., 2011. Perturbation of hepcidin expression by BMP type I receptor deletion induces iron overload in mice. Blood 118, 4224-4230.

Stevens, R.G., Jones, D.Y., Micozzi, M.S., Taylor, P.R., 1988. Body iron stores and the risk of cancer. N. Engl. J. Med. 319, 1047-1052.

Suda, T., Udagawa, N., Takahashi, N., 1996. Cells of Bone: Osteoclast Generation. Academic Press, San Diego.

Szalay, F., 2013. Hemochromatosis: one form of iron-overload diseases. Orv. Hetil. 154, $1156-1164$

Tanno, T., et al., 2011. Hepcidin, anaemia, and prostate cancer. BJ. Int. 107, 678-679.

Tsay, J., et al., 2010. Bone loss caused by iron overload in a murine model: importance of oxidative stress. Blood 116, 2582-2589.

Valenti, L., Varenna, M., Fracanzani, A.L., Rossi, V., Fargion, S., Sinigaglia, L., 2009. Association between iron overload and osteoporosis in patients with hereditary hemochromatosis. Osteoporos. Int. 20, 549-555.

Wu, T., Sempos, C.T., Freudenheim, J.L., Muti, P., Smit, E., 2004. Serum iron, copper and zinc concentrations and risk of cancer mortality in US adults. Ann. Epidemiol. 14, 195-201.

Wu, X., et al., 2012. Hepcidin regulation by BMP signaling in macrophages is lipopolysaccharide dependent. PLoS One 7, e44622.

Yamasaki, K., Hagiwara, H., 2009. Excess iron inhibits osteoblast metabolism. Toxicol. Lett. $191,211-215$.

Zhang, W., et al., 2013. Role and mechanism of microglial activation in iron-induced selective and progressive dopaminergic neurodegeneration. Mol. Neurobiol. http://dx.doi.org/10.1007/s12035-013-8586-4. 